\title{
Surgical abortion at twenty weeks: is morality determined solely by the outcome?
}

\author{
Richard J Lilford and Nicholas Johnson St Fames's University Hospital, Leeds
}

\section{Author's abstract}

A strong body of opinion contends that late terminations of pregnancy are better carried out by surgical methods. We show that the suggested advantages of greater safety and patient acceptance are based on out-of-date or inaccurate (biased) data. The advantages of medical methods are, however, equally unproven. However, we argue that the adverse emotional and symbolic effects of late surgical termination have moral force. We therefore contend that in the absence of strong patient preference, medical termination is the preferable method, and will remain of that opinion unless clear demonstration of the greater safety of surgical methods can be made at some future date.

When conducting a termination of pregnancy at 20 weeks' gestational age, the cervix may be manually dilated and the fetus removed piecemeal, or contractions may be induced and following labour the baby delivered whole. The former procedure has been advocated on the grounds that it is safer $(1,2)$ but more particularly that it is less offensive to the patient. Instead of enduring many hours of contractions and delivering in full awareness, the woman goes to theatre pregnant and comes back with the procedure completed. The first of these putative advantages is controversial (3), since both methods are extremely safe, and they have never been compared in an unbiased, controlled or randomised study examining the mortality and major physical morbidity of each method. The evidence is 10 years old $(4,5,6,1)$ and based mostly on comparison of surgical methods (in centres of excellence) with outdated medical techniques such as intra-amniotic hypertonic saline infusion. The less traumatic current medical methods with extra-amniotic prostaglandins or oral progesterone antagonists are much safer (7). Surgical methods can damage the cervix $(8,9,10)$ and this may lead to recurrent late abortion in subsequent pregnancies $(11,12,13,14,15)$. However, modern data do not support this (16). The Royal College of

\section{Key words}

Surgical abortion; termination of pregnancy; pregnancy trimester second; pregnancy unwanted; ethics; morals.
Obstetricians and Gynaecologists believes that the question of safety will persist until a prospective randomised trial establishes the various merits of the different methods (17).

The second advantage, that surgical methods are psychologically preferable, is also not clear-cut. Women having a termination of pregnancy at 20 weeks of gestation are not necessarily emotionally indifferent to their fetuses. We think they are likely to have feelings of affection and perhaps even reverence for their fetus and that in choosing termination of pregnancy they are selecting what they would regard as the lesser of two evils. It could be argued that, providing the patient does not realise that the baby is dismembered and delivered piecemeal, then 'what the eye does not see, the heart does not grieve over'. Thus, provided the potential mother is not told 'all the details', she may suffer a net psychological benefit from the surgical method of termination of pregnancy. Whilst Kaltreider et al, (11) suggest this, their study groups were unrandomised, biased and the work subject to methodological shortcomings. There are two further objections to this line of argument. The first is that to withhold this information represents a conscious choice to deny full knowledge, in order to spare suffering; in the philosopher's jargon, beneficence is given greater weight than autonomy. This argument would have considerable utilitarian value if it was not for a second consideration: the issue of termination of pregnancy and how it is procured is in the public domain. This is inevitably a matter of common interest. It is an issue on which society will have a view and in which law must play a part. These laws must result from public debate in a democratic country. Thus it is inevitable that the details of termination of pregnancy will become public knowledge. People who have had late terminations of pregnancy will know, albeit retrospectively, in grisly and precise detail, how this operation may have been performed. Indeed, Mr David Alton has made much of this from many public platforms and has been widely quoted on television and in newspapers. There must be few people in our nation who have had 20-week surgical terminations of pregnancy and who do not know how this may be carried out. 'Pro-Life' organisations have produced dramatic films claiming 
to show the fetus screaming as it is surgically dismembered. If patients knew that a surgical termination of pregnancy involved removing the fetus piecemeal and that the pieces were then collected and reassembled like a jigsaw it is doubtful that many women would find the surgical method psychologically preferable. Suction termination in the first trimester involves similar physical destruction but:

1) the fetus is not perceived in the same way,

2) the destruction is instantaneous,

3) the destruction is mechanical, not manual and deliberate.

Despite many reports proclaiming the advantages of surgical terminations, there are few recent detailed studies comparing the psychological effects of each method. In the absence of adequate evidence either way the remainder of the argument will be conducted on the assumption that most women are indifferent between these two methods.

Before turning to the main theme of the analysis, we wish to consider a further aspect. This concerns the effect on third parties, namely nursing staff. In the case of medical induction of labour, extra strain is placed on ward staff who must effect the delivery. In the case of surgical termination of pregnancy, this strain is transferred to operating theatre staff who must see the dismemberment of the fetus, or at least be aware that this is taking place in the operating theatre in which they work. Again it is impossible to judge whether the starker and more dramatic surgical method is more acceptable to staff than delivery on the ward. It might be argued that theatre staff are more familiar with and therefore able to withstand the emotional impact of termination of pregnancy, despite the fact that this might be aesthetically more gruesome. Furthermore, it might be argued that doctors who are responsible for making the decision should share it with nursing staff and that this is more likely to happen in theatre. This argument presupposes that sharing the experience with a doctor ameliorates some of the distress of late temination of pregnancy. Again, this issue can be argued both ways and again we will assume that the psychological effects on nursing staff of both methods of termination of pregnancy are equal.

We have now concluded that there is no scientific reason to prefer one method over the other from the point of view of patient psychology, safety or effects on nursing third parties. What about the effects on the fetus? With both methods of termination of pregnancy the fetus will die. Of course, if the fetus were to suffer more with one method than the other, then the sentience of the fetus would have a moral bearing on the choice, and would have to be considered. There is no doubt the 20-week fetus reacts to pain (18), it will withdraw its arm from a painful stimulus. Does this mean that it suffers pain in the sense we know and understand it? This is impossible to prove as pain is subjective. While few would argue that the fetus suffers pain in the same sense and with the same intensity as, say, a three-year-old child, it would be surprising if withdrawal was purely on the basis of reflex arc and that the fetus was not subject to at least a small amount of 'cortical' recognition of pain.

Of course, it could be suggested that the process of labour also causes pain, but the absence of crying following a gentle delivery, together with lack of fetal heart rate acceleration during normal delivery, argue against this. We think that, for the time being, we can argue that any additional pain felt by the fetus during surgical termination of pregnancy is likely to be so poorly perceived centrally and so short-lived, that it has a relatively small impact on our decision.

We have now decided that both methods of termination of pregnancy may be presumed to be, at least in our present state of uncertainty, equally safe, equally disliked by the mother, and equally disliked by staff. As far as the fetus is concerned, the overwhelming consideration is that at the end of the procedure it will be dead and that any moment of pain must be regarded as a small consideration in the face of this stark reality.

Given that the outcome for the fetus is virtually identical, we would now like to turn our attention to determining whether both methods of termination of pregnancy are therefore morally equivalent. If they are equivalent, then the issue will depend solely on further empirical evidence. (It is possible, of course, that in future we will have such evidence, but that it will be conflicting. If it were proved, for example, that surgical termination was safer but more psychologically offensive, then we would have to make a value trade-off between these two considerations).

The claim could be made that if the results for the baby, nursing staff and patient are regarded as being the same with both methods, then the two methods are morally equivalent. The alternative deduction is that the emotional violation of physical termination of pregnancy renders this morally worse, even if all other factors are equal. In other words, we can argue that the means by which the destruction of the fetus is accomplished has moral significance in its own right. However, this cannot be argued on purely intrinsic grounds; we shall have to argue that a disadvantage of surgical methods hinges on the emotional and symbolic impact of these procedures. It will be noticed that in the above debate we made no claim that the two methods are equally offensive to doctors. It is clear that physically dismembering and removing the fetus is emotionally more distressing for the doctor. A doctor, therefore, has to overcome an element of emotional revulsion in order to do a late surgical termination of pregnancy. The argument that 'medical' termination is preferable because surgical methods distress the doctor is, by itself, a weak argument because much of the basis for medical practice is that the doctor should put a patient's interests above his or her own; that a good doctor should be prepared to make a personal sacrifice on behalf of his or her patient. The argument does not, 
however, end with this. Our argument hinges not only on the doctor's feelings, but on the feelings of others who know that medical practitioners carry out this form of destructive surgery. We believe that the symbolic significance of manual fetal destruction has force. Thus we would claim dismemberment of the baby so violates a general human instinct that it is morally worse than destruction of the fetus by other means.

It is brutally materialistic to insist that the two methods are equivalent simply because the fetal outcome is the same, since this ignores the moral dimension of human emotion. We would contend that, while it is wrong to be guided solely or even mainly by emotion, it is equally wrong to ignore emotion or pretend that it does not or should not exist or influence the way we behave. To illustrate this further we would borrow a story within a story - a chapter in John Fowles's book The Magus (19). Here the village mayor agrees to kill a resistance fighter captured by the Gestapo, but is unable to do so when he finds that his gun is unloaded and that he is expected to destroy the captive with the rifle butt. Few people could read this poignant account without realising that physical brutality has specific moral disadvantages, over and above the means to which it is put. Thus whilst individuals within our society hold different moral positions on abortion (a spectrum ranging from indifference to intolerance) the majority intuitively feel that surgical dismemberment is more abhorrent than a medical termination of pregnancy.

Mr David Alton realises this and he frequently cites the method by which surgical termination is conducted in his campaign against existing British abortion legislation. This abhorrence shows that there is a genuine moral difference between the two methods, a medical procedure being more acceptable and less offensive than a surgical approach. However, the intuitive feeling that a particular act is abhorrent should not be made to justify its abolition. We must distinguish emotions which represent the positive desire to help from those that are negative or undesirable. There are many examples of negative or undesirable emotions. In the past our society objected to certain practices (for example homosexuality, interracial sexual relationships, suicide, mercy killing) and our current moral outlook suggests that we should overcome the negative emotions that underlie these reactions. The situation is quite different when the emotion is not linked to a negative emotion. Positive emotions should not be ignored, they should be regarded as a moral force in their own right and these 'good' emotions are affronted by the physical dismemberment of the fetus. It is right to wring the neck of an injured bird but it is also right to choose a less gruesome method if it is available.

This difference between different actions with the same outcome has considerable intuitive appeal to the majority of people. We think our arguments demonstrate that this intuitive appeal can be defended on moral grounds, and this has applications to morality quite outside medicine, for example in the morality of the conduct of war. We would take the line that detonation of a bomb under direct vision by remote control is morally worse than use of a time-set device the former involves an additional violation, although both acts are so horrible by their intention to kill and maim, that additional considerations might 'pale into insignificance'. Nevertheless, the symbolic value of actions should be discussed in all ethical problems, for, as Plato emphasises in The Republic (20), all moral problems are connected.

In conclusion, we believe that the arguments against the surgical method of late termination of pregnancy are strong. Firstly, the data suggesting that the surgical termination of pregnancy is safer are the result of enormous selection bias and are out of date. Furthermore, unless laminaria are used (slowly expanding slivers of seaweed placed in the cervix), the cervix must be dilated further for this to be achieved, and it is possible that this could lead to recurrent fetal loss in future pregnancies $(12,13,14,15)$. Furthermore, we suspect that many people having a 20-week termination of pregnany would prefer to know that their baby had been delivered with dignity; many people now request to see the baby even when the termination was requested for psychosocial reasons. The distress to nursing staff can be argued both ways. Morally, physical dismemberment of the fetus is less preferable because of its symbolic significance, quite apart from the distress this causes the doctor.

Means are not as important as ends, but they should not be ignored; some emotions are part of the beauty, and therefore, perhaps, the morality of human life. It is not always essential to suppress our emotions in order to make the best decisions.

Richard F Lilford MRCOG MRCP PhD is Professor of Obstetrics and Gynaecology at St Fames's University Hospital, Leeds, LS9 7TF and Nicholas Johnson MRCOG FRCS is a Lecturer in the Department of Obstetrics and Gynaecology at the same hospital.

\section{References}

(1) Grimes D A, Schulz K F, Cates W Jr, Tyler C W. Midtrimester abortion by dilatation and evacuation. A safe and practical alternative. New England journal of medicine 1977; 296:1141-1145.

(2) Potts M, Diggery P, Peel J. Abortion. Cambridge: Cambridge University Press, 1977.

(3) Schulman H. Discussion summary. In: Zatuchni G I, Sciarra J J, Speidel J J, eds. Pregnancy termination: procedures, safety and new developments. Hagerstown, Maryland: Harper and Row, 1979: Ch 30, 250-251.

(4) Cadesky K I, Ravinski E, Lyons E R. Dilatation and evacuation: a preferred method of midtrimester abortion. American journal of obstetrics and gynecology $1981 ; 139: 329-332$.

(5) Cates W, Grimes D A. Deaths from second trimester abortion by dilatation and evacuation: cause, prevention, facilities. Obstetrics and gynecology 1981; 
58:407-408.

(6) Grimes D A, Hulka J F, McCutchen M E. Midtrimester abortion by dilatation and evacuation versus intraamniotic instillation of prostaglandin $F_{2}$ alpha: a randomised clinical trial. American journal of obstetrics and gynecology 1980; 137:785-790.

(7) Lauersen N H. Induced abortion. In: Bygdeman M, Berger G S, Keith G, eds. Prostaglandins and their inhibitors in clinical obstetrics and gynaecology. Lancaster: MTP Press, 1986: Ch 15:271-314.

(8) Anonymous. Late consequence of abortion [editorial]. British medical journal 1981; 282:1564-1565.

(9) Johnstone F D, Beard R J, Boyd I E et al. Cervical diameter after suction termination of pregnancy. British medical journal 1976; 1:68-69.

(10) Hulka J F, Lefler H T Jr, Anglone A et al. A nonelectronic force monitor to measure factors influencing cervical dilatation for vacuum curettage. American journal of obstetrics and gynecology 1974; 120,2:166-173.

(11) Kaltreider N B, Goldsmith S, Margolis A J. The impact of midtrimester abortion techniques on patients and staff. American journal of obstetrics and gynecology 1979:135 and 235-238.

(12) Wright C S W, Campbell S, Beazley J. Second trimester abortion after vaginal termination of pregnancy. Lancet
$1972 ; 1: 1278-1279$.

(13) Richardson J A, Dixon G. Effects of legal termination on subsequent pregnancy. British medical journal 1976; $1: 1303-1304$.

(14) Liu D T Y, Melville H A H, Martin T. Subsequent gestational morbidity after various types of abortion. Lancet 1972; 2:431.

(15) World Health Organisation Task Force on the sequelae of abortion. The association of induced abortion with adverse outcome in subsequent pregnancy. In: Sciarra J $\mathrm{J}$ et al eds. Risks, benefits and controversies in fertility control. Hagerstown, Maryland: Harper and Row, 1979: 368-389.

(16) Houge C R J, Cates W, Tietze C. The effects of induced abortion on subsequent reproduction. Epidemiology review 1982; 4:66-94.

(17) Stanwell-Smith R. Late abortion in England and Wales. In: Alberman E, Dennis K J, eds. Report of a national confidential study by the Royal College of Obstetricians and Gynaecologists, 1984. Royal College of Obstetricians and Gynaecologists, 1984: Ch 3, 64.

(18) Valman H B, Pearson J F. What the fetus feels. British medical journal 1980; 280:233-234.

(19) Fowles J. The magus. London: Pan books, 1988.

(20) Plato. Republic. Harmondsworth: Penguin, 1970.

(Continued from page 60)

\section{References}

(1) Colman R D. The ethics of general practice and advertising. Fournal of medical ethics 1989; 15:85-88.

(2) Brahams D. Doctors and advertising. Lancet 1988; ii: 1434 .

(3) Monopolies and Mergers Commission. Services of medical practitioners - a report on the supply of the services of registered medical practitioners in relation to restrictions on advertising. London: HMSO, 1989: Cm 582.
(4) See reference (3): 34-37.

(5) See reference (3): 37-39.

(6) See reference (3): 32-33.

(7) See reference (3): 48-49.

(8) Declaration of Lisbon. In: British Medical Association. The handbook of medical ethics. London: BMA, 1984: 72.

(9) See reference (3): 47.

(10) See reference (3): 45.

(11) See reference (3): 50-51.

(12) See reference (3): 52. 